\title{
VEHICLE TRACK INTERACTION SAFETY STANDARDS
}

\author{
Brian Marquis \\ Jon LeBlanc \\ Volpe National Transportation Systems Center \\ US Department of Transportation \\ Cambridge, MA, USA
}

\author{
Ali Tajaddini \\ Federal Railroad Administration \\ Office of Research and Development \\ US Department of Transportation \\ Washington, DC, USA
}

\section{ABSTRACT}

Vehicle/Track Interaction (VTI) Safety Standards aim to reduce the risk of derailments and other accidents attributable to the dynamic interaction between moving vehicles and the track over which they operate. On March 13, 2013, the Federal Railroad Administration (FRA) published a final rule titled "Vehicle/Track Interaction Safety Standards; High-Speed and High Cant Deficiency Operations" which amended the Track Safety Standards (49 CFR Part213) and the Passenger Equipment Safety Standards (49 CFR Part 238) in order to promote VTI safety under a variety of conditions at speeds up to $220 \mathrm{mph}$. Among its main accomplishments, the final rule revises standards for track geometry and enhances qualification procedures for demonstrating vehicle trackworthiness to take advantage of computer modeling.

The Track Safety Standards provide safety limits for maximum allowable track geometry variations for all nine FRA Track Classes - i.e., safety "minimums." These limits serve to identify conditions that require immediate attention because they may pose or create a potential safety hazard. While these conditions are generally infrequent, they define the worst conditions that can exist before a vehicle is required to slow down. To promote the safe interaction of rail vehicles with the track over which they operate (i.e. wheels stay on track, and vehicle dynamics do not overload the track structure, vehicle itself, or cause injury to passengers), these conditions must be considered in the design of suspension systems. In particular, rail vehicle suspensions must be designed to control the dynamic response such that wheel/rail forces and vehicle accelerations remain within prescribed thresholds (VTI safety limits) when traversing these more demanding track geometry conditions at all allowable speeds associated with at particular track class.

To help understand the differences in performance requirements (design constraints) being placed on the design of passenger equipment suspensions throughout the world, comparisons have been made between FRA safety standards and similar standards used internationally (Europe, Japan, and China) in terms of both allowable track geometry deviations and the criteria that define acceptable vehicle performance (VTI safety limits). While the various factors that have influenced the development of each of the standards are not readily available or fully understood at this time (e.g., economic considerations, provide safety for unique operating conditions, promote interoperability by providing a railway infrastructure that supports a wide variety of rail vehicle types, etc.), this comparative study helps to explain in part why, in certain circumstances, equipment that has been designed for operation in other parts of the world has performed poorly, and in some cases had derailment problems when imported to the U.S. Furthermore, for specific equipment that is not specifically designed for operation in the U.S., it helps to identify areas that may need to be addressed with other appropriate action(s) to mitigate potential safety concerns, such as by ensuring that the track over which the equipment is operating is maintained to standards appropriate for the specific equipment type, or by placing operational restrictions on the equipment, or both.

In addition to these comparisons, an overview of the new FRA qualification procedures which are used for demonstrating vehicle trackworthiness is provided in this paper. These procedures, which include use of simulations to demonstrate dynamic performance, are intended to give guidance to vehicle designers and provide a more comprehensive tool for safety assessment and verification of the suitability of a particular equipment design for the track conditions found in the U.S.

\section{INTRODUCTION}

Track geometry is one of the largest factors affecting VTI safety, Figure 1. In development of FRA's final VTI rule, it conducted a set of engineering and vehicle track dynamic interaction simulation studies to establish a set of standards that 
would ensure safety in the envisioned speed ranges. These studies were the basis for set of limits on alinement, surface, gage, crosslevel, and track warp, which are progressively tighter for higher speeds and are used for measurement and inspection of track geometry. The chord lengths and associated mid-chord offsets were selected to control irregularities over the full range of wavelengths likely to affect vehicle dynamics and ride vibration over the range of speeds. These studies modeled the effect of specific track geometry defects on candidate vehicles, including the response of an Amfleet Amcoach, an AEM-7 locomotive, a Genesis Locomotive, and an Acela Power Car and Acela Coach Car, to single and repeated surface and alignment deviations.

An extensive matrix of simulation studies involving all five vehicle types was used to determine the amplitude of track geometry alinement anomalies, surface anomalies, and combined surface and alinement anomalies that result in undesirable response defined by the VTI safety limits. These simulations were performed using two coefficients of friction (0.1 and 0.5), two analytical anomaly shapes (bump and ramp), and combinations of speed, curvature, and superelevation to cover a range of cant deficiency. The results provided the basis for establishing the revisions to the geometry limits adopted in this final rule.

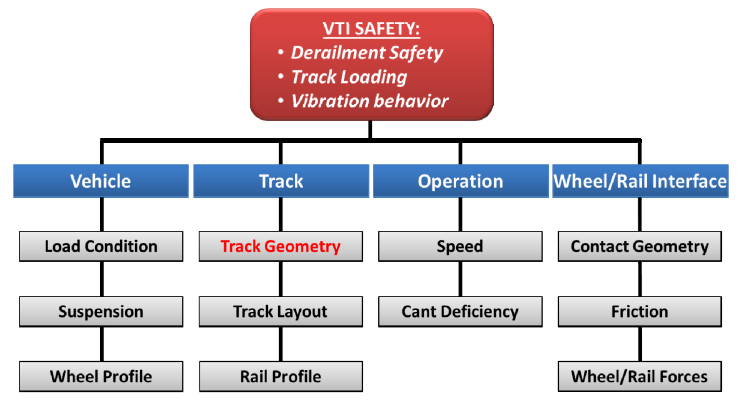

Figure 1: Various factors affecting VTI Safety

Under FRA regulations, each railroad has primary responsibility to ensure its track meets or exceeds the federal track geometry safety limits. While most railroads internally adopt tighter track geometry maintenance limits, in order to ensure safety, vehicles in general must be designed to operate over the safety limits.

\section{TRACK GEOMETRY LIMITS (VEHICLE INPUTS)}

Figure 2 shows a comparison of allowable geometry variations permitted by four different international standards namely, those of Japan, China, the United States, and Europe. Each of these standards has established safety limits (or immediate action limits) on track geometry variations that have the potential to create unsafe operating conditions in train operation up to $220 \mathrm{mph}$. These limits in general are progressively tighter for higher speeds. However, the speed ranges used are different, summarized in Table 1, making a direct comparison between standards difficult.
Table 1: Speed Ranges used in different Track Standards.

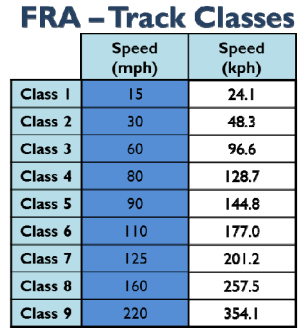

Japanes Speed Ranges

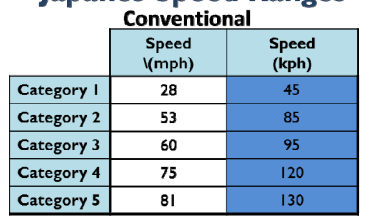

\section{EN I 3848 Speed Ranges}
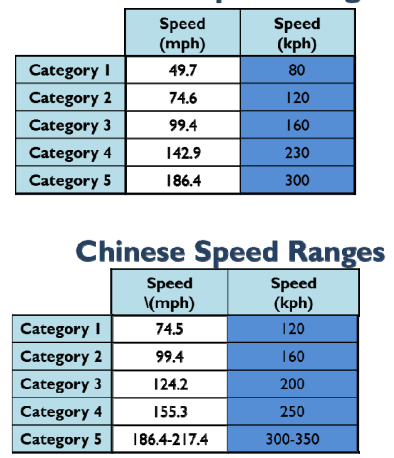

Furthermore, each of these standards uses a different procedure for limiting track geometry variations. For example, in the US track safety standards, 49 CFR 213, the maximum amplitude of surface and alinement variations is limited by restricting the maximum deviation from uniformity rail at the midordinate of a chord (MCO). A similar procedure is used in Japan. However, in both China and Europe, the maximum amplitude of surface and alinement variations is limited by restricting the zero-to-peak value and mean-to-peak value of filtered space curve geometry respectively.

In spite of these differences, a comparison was made between the various international limits in order to assess differences in vehicle design requirements. The comparative analysis presented in Figure 2 was done using versine to represent the shape of a typical geometry variation. In this analysis, the amplitude of variation was increase until the limits in each standard was reached. This was repeated for each of the overlapping speed ranges for a range of wavelengths from 5 to 200 feet. To that end, the series of charts shown in Figure 2 map out the maximum geometry variations allowed by each of the different standards as a function of speed and wavelength. The areas shown in shading are the conditions that would be detected as a defect by a geometry inspection car. The white areas below are conditions that would be deemed safe by a geometry inspection car and must be considered in the design of a vehicle suspension system.

In general, this comparison shows FRA track geometry limits allow larger short wavelength perturbations at very low speeds, but are more restrictive at long wavelengths in the middle speed bands. The comparison also shows that the differences are larger for lower track classes (track classes 1-3) and smaller, and in some cases negligible, for higher track classes.

It should be noted that while the newer FRA track geometry limits are based on simulation studies, some older lower track class limits have been developed based on testing and/or experience. This appears to be true for many of the international standards as well. 



Figure 2: Comparison of track geometry standards 

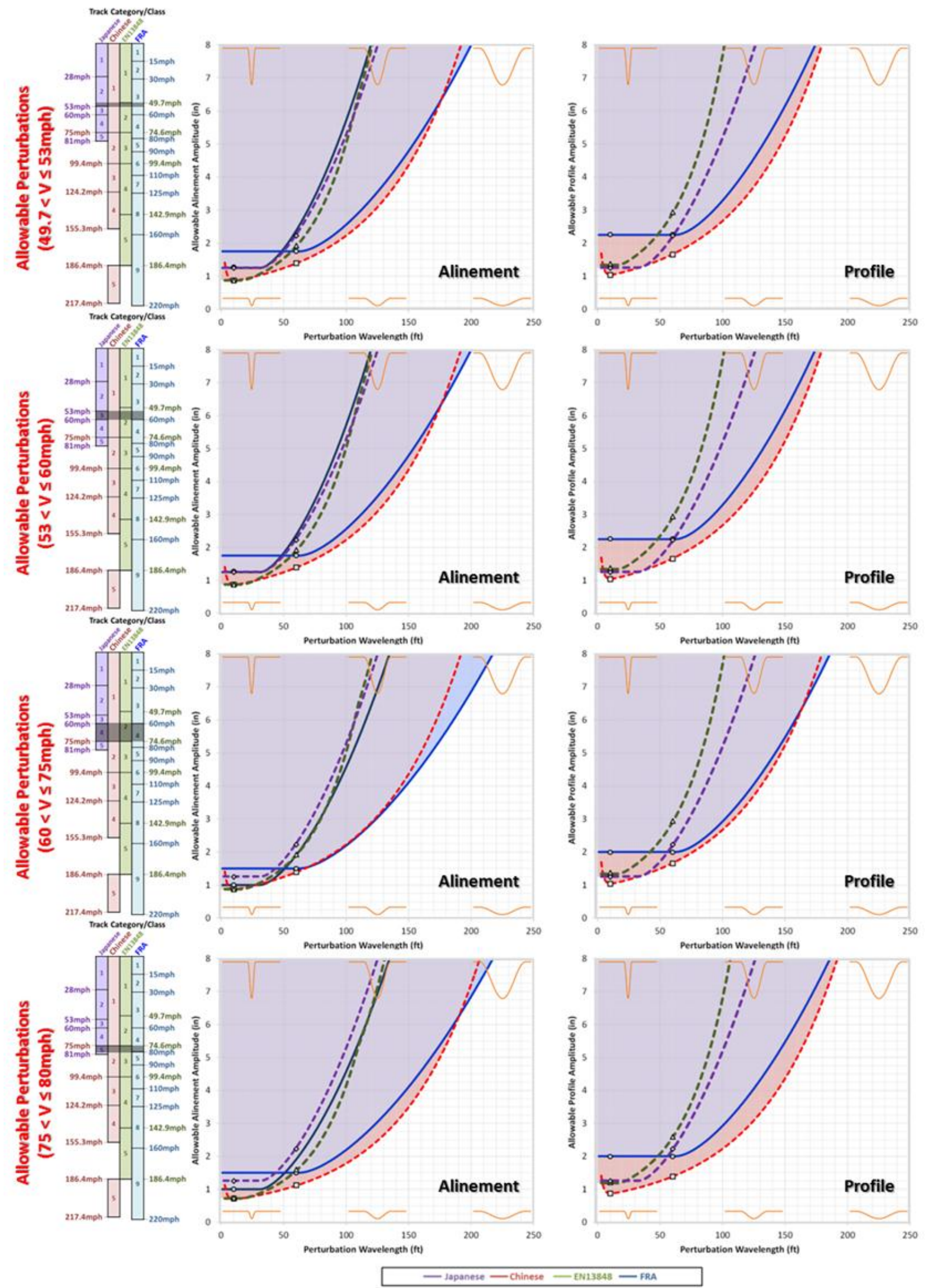

Figure 2 - continued: Comparison of track geometry standards 

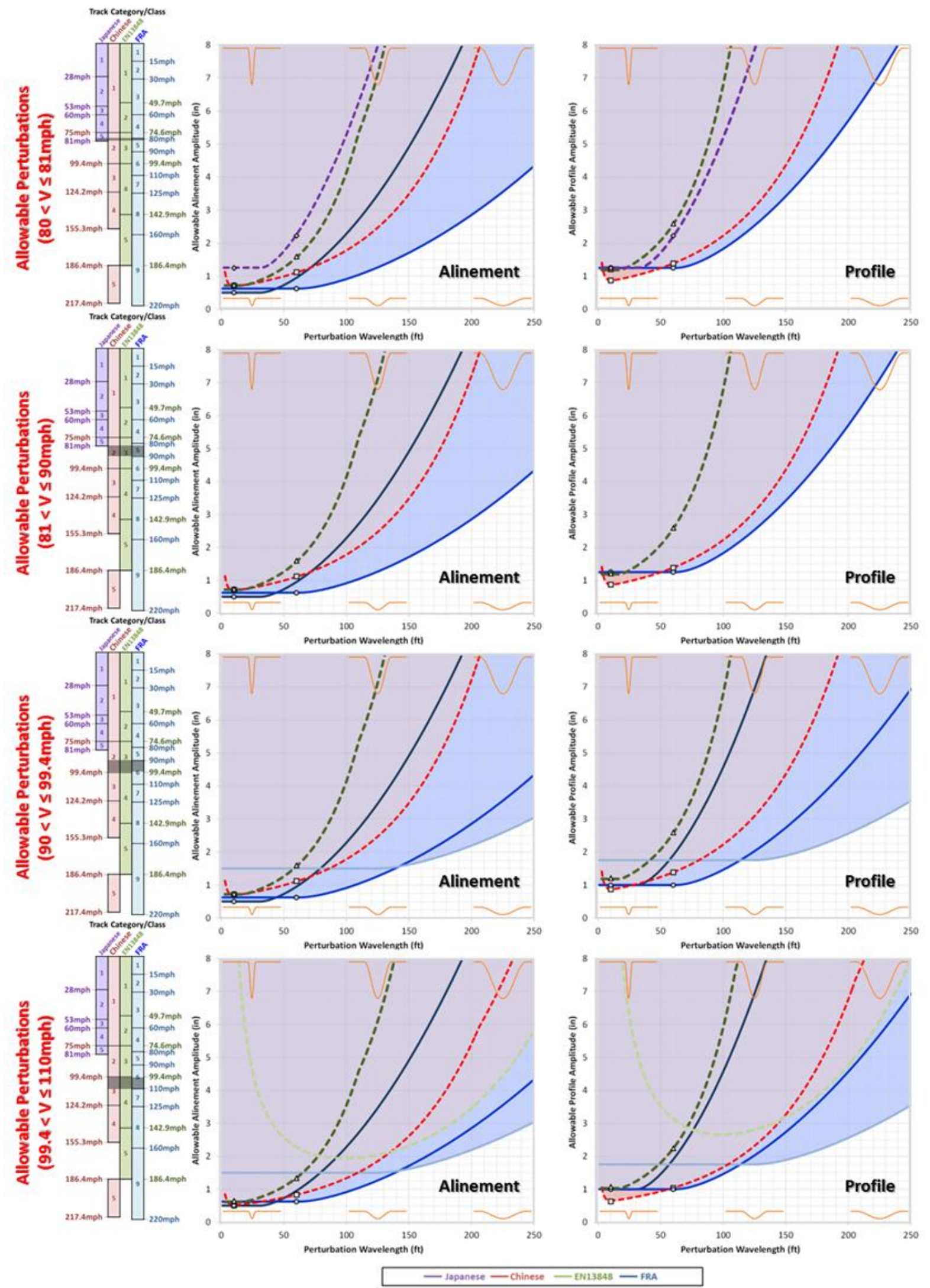

Figure 2 - continued: Comparison of track geometry standards 

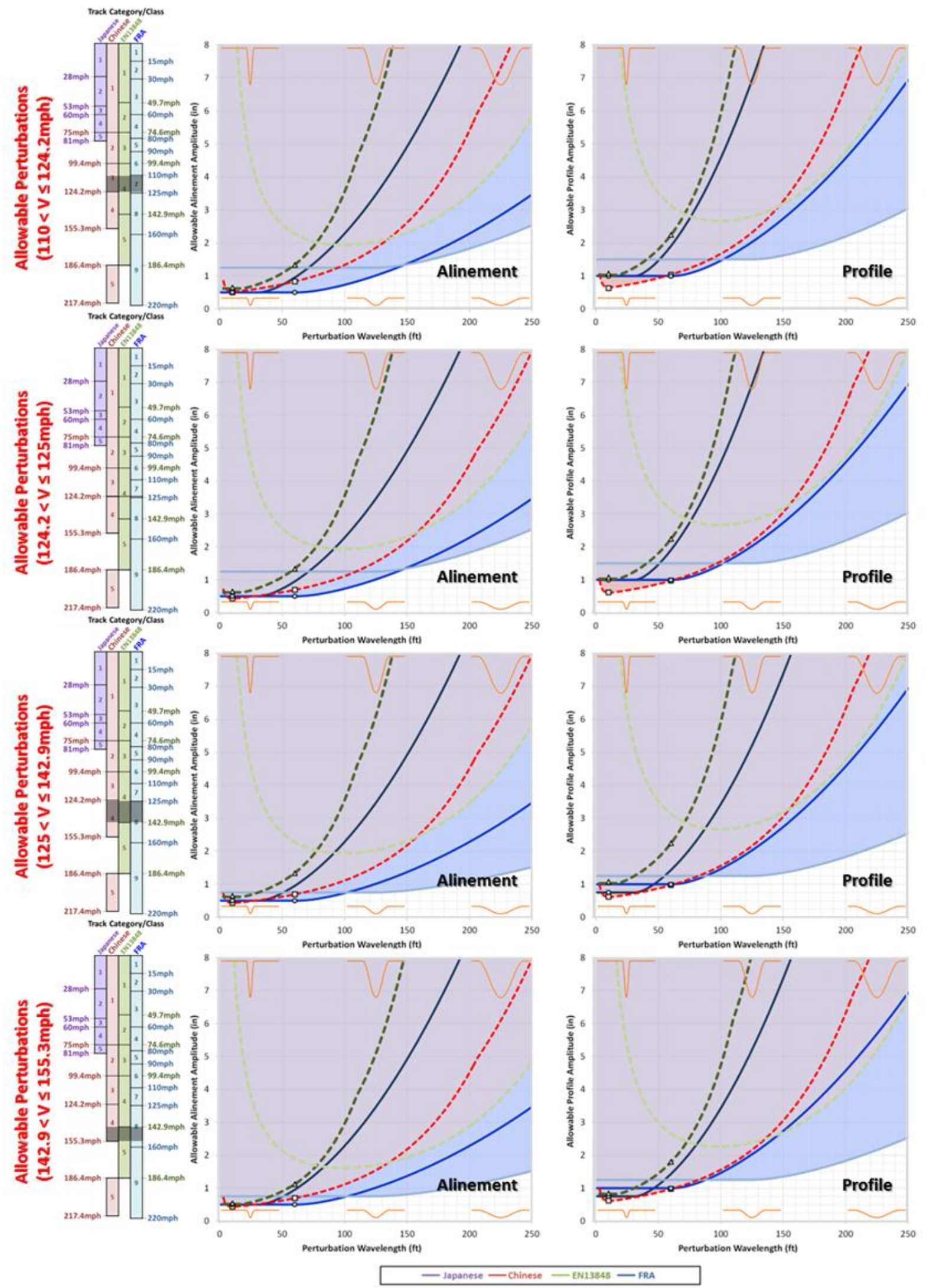

Figure 2 - continued: Comparison of track geometry standards 

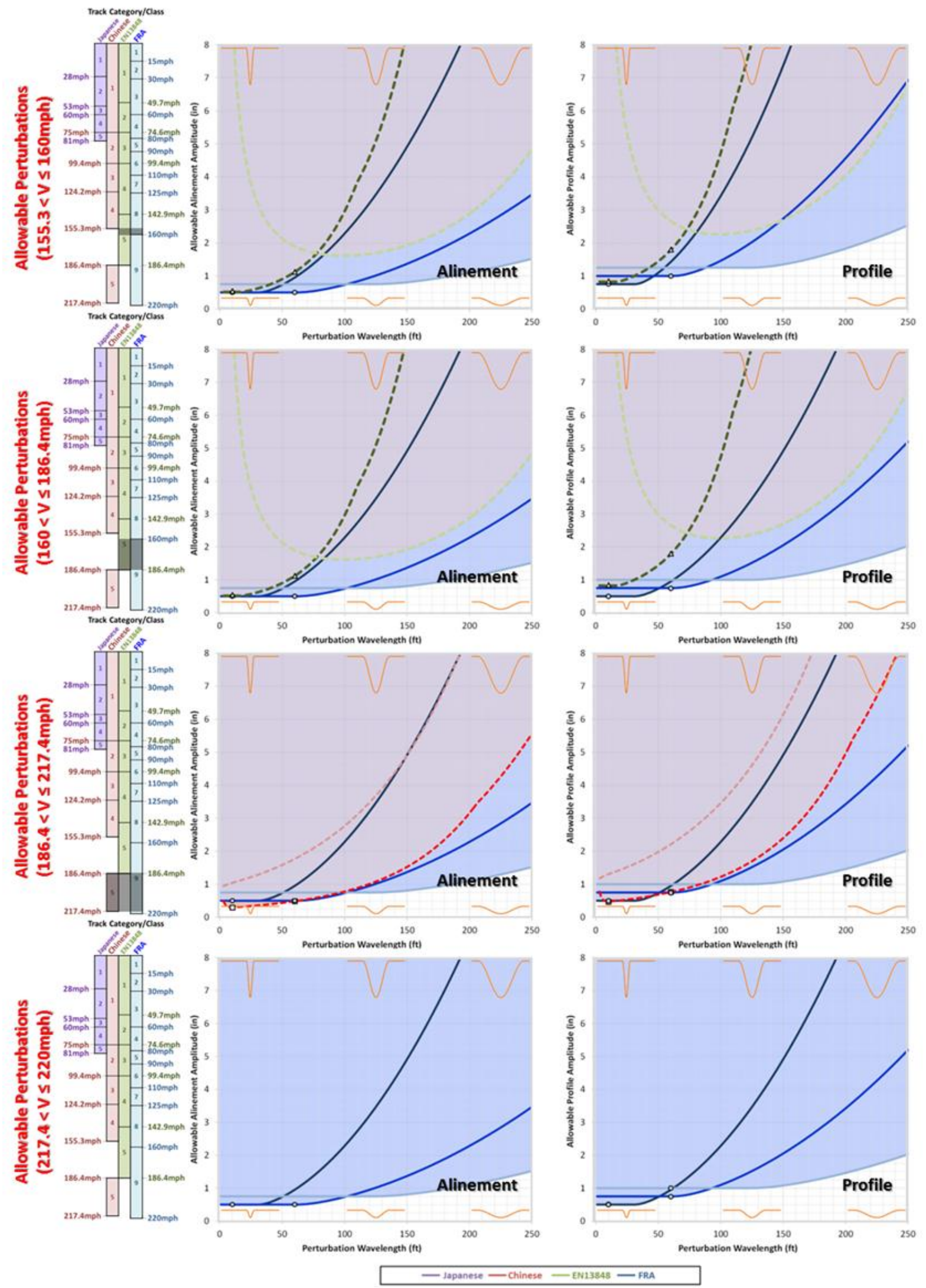

Figure 2 - continued: Comparison of track geometry standards 
Figure 3 shows, as a function of speed, the maximum allowable amplitude of a variation having wavelength equal to 10 feet, typical axle spacing in a passenger truck. This comparison shows FRA track geometry limits for both profile and alinement allow larger short wavelength perturbations at very low speeds, but are more restrictive at short wavelengths at higher speeds. These larger amplitude short wavelength variations found on lower speed track classes have been found at some of the derailments experienced with equipment imported into the U.S.
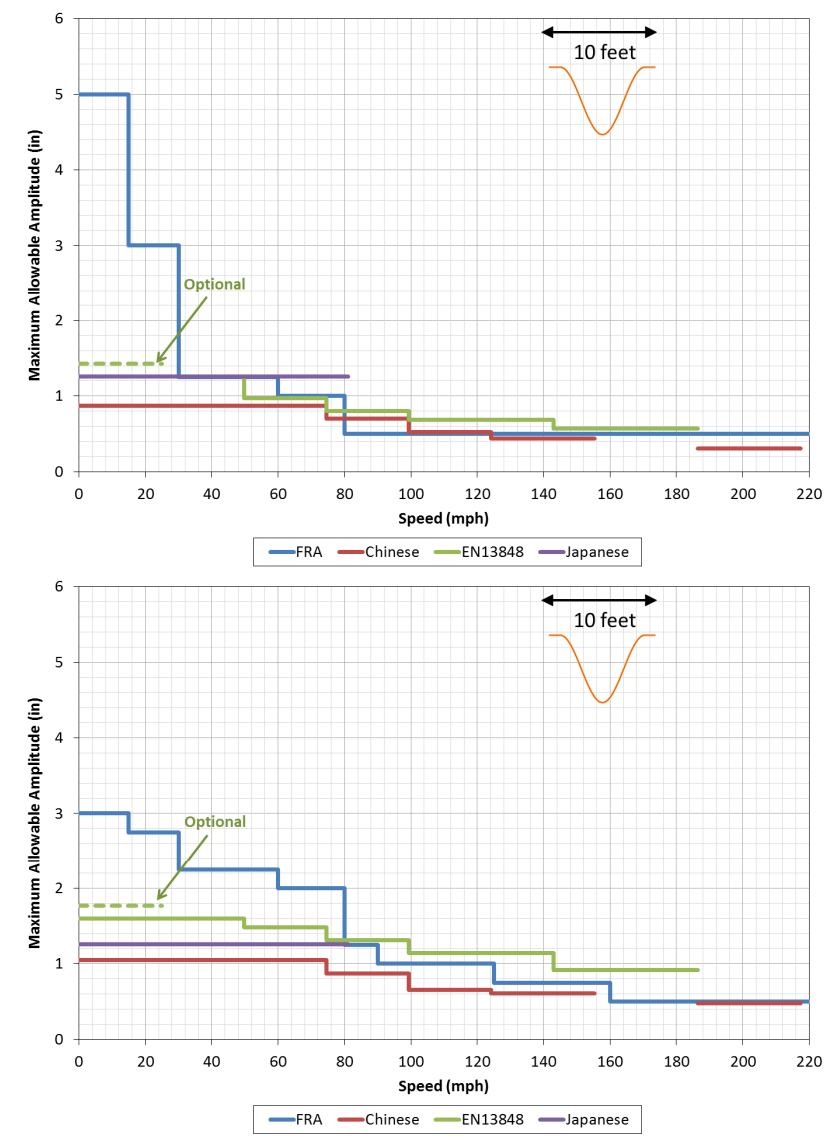

Figure 3: Allowable geometry vs. speed, $\lambda=10$ feet

Figure 4 shows, as a function of speed, the maximum allowable amplitude of a variation having wavelength equal to 60 feet, typical truck spacing in a passenger car. This comparison shows FRA track geometry limits for alinement allow larger mid wavelength perturbations at very low speeds, but are more restrictive for profile mid wavelength perturbations at very low speeds. The comparison also shows that FRA track geometry limits for both alinement and surface at is more restrictive for mid wavelength perturbations at higher speeds.
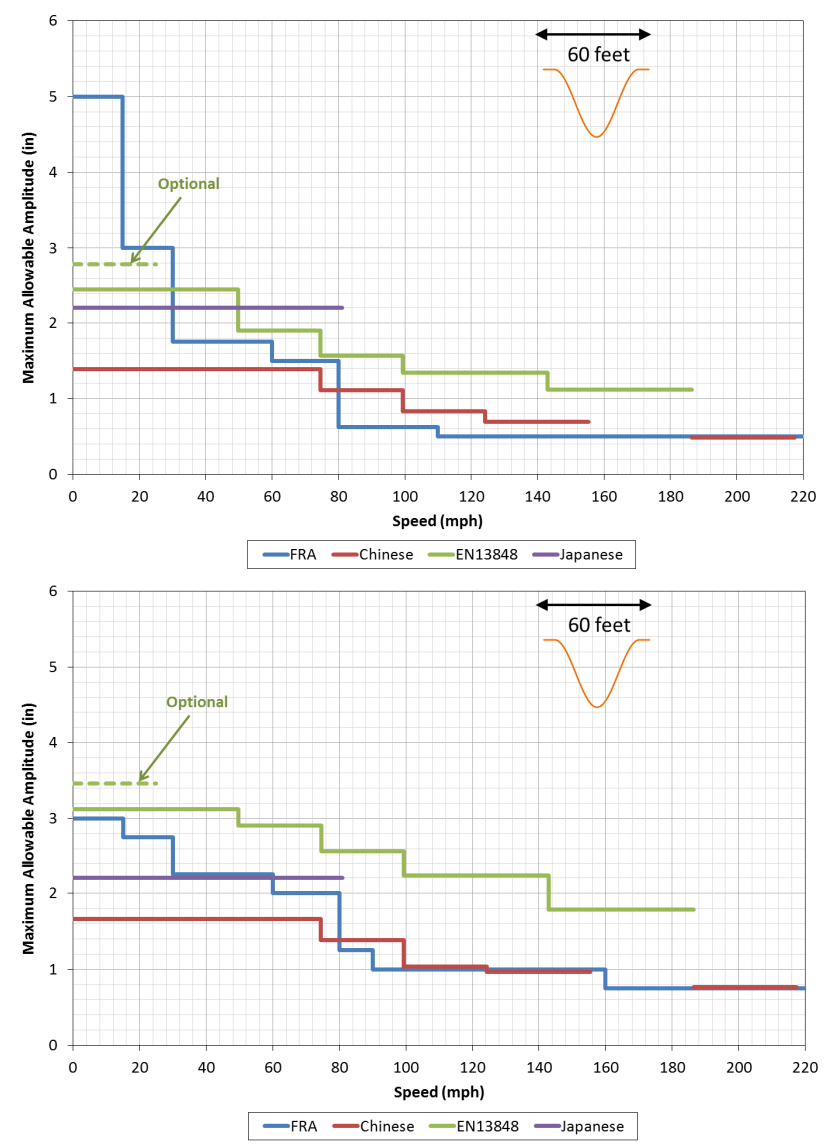

Figure 4: Allowable geometry vs. speed, $\lambda=60$ feet

\section{VTI SAFETY LIMITS (LIMIT ON VEHICLE RESPONSE)}

While track geometry limits define the worst case track conditions (inputs) that a vehicle must be able to negotiate safely, VTI Safety Criteria, which are limits on wheel/rail forces and vehicle accelerations, define how well the vehicle must perform operating over the allowable track conditions in order to ensure safety. For that reason, both track geometry limits and VTI safety criteria together are constraints on a vehicle design, as shown in Figure 5. To have a total understanding of the VTI related constraints influencing suspension design, an understanding of both elements is necessary. It is not sufficient to consider track geometry standards alone since changes to either element will have an effect on a given suspension design. 


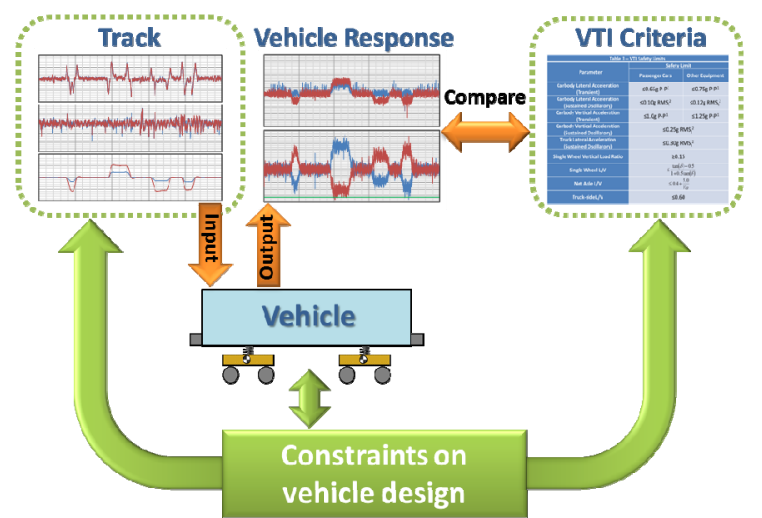

Figure 5: Influence of track geometry limits and VTI Safety Limits on Vehicle Design

Table 2 summarizes the FRA VTI Safety Criteria found in 49 CFR 213.333. These limits on wheel/rail forces and vehicle accelerations are intended to promote the safe interaction of rail vehicles with the track over which they operate. In particular they ensure that wheels stay on track, and vehicle dynamics do not overload either the track or vehicle, or cause injury to passengers.

Table 2: FRA VTI Safety Criteria (49 CFR 213.333).

\begin{tabular}{|c|c|c|c|}
\hline \multirow[b]{2}{*}{ Parameter } & \multicolumn{2}{|c|}{ SafetyLimit } & \multirow[b]{2}{*}{ Filter/Window } \\
\hline & Passenger Cars & $\begin{array}{c}\text { Other } \\
\text { Equipment }\end{array}$ & \\
\hline $\begin{array}{c}\text { Carbody Lateral } \\
\text { Acceleration (Transient) } \\
\end{array}$ & $\leq 0.65 \mathrm{~g} P-\mathrm{P}^{1}$ & $\leq 0.75 \mathrm{~g}^{\mathrm{P}-\mathrm{P}^{1}}$ & 1 sec window \\
\hline $\begin{array}{c}\text { Carbody Lateral } \\
\text { Acceleration (Sustained } \\
\text { Oscillatory) } \\
\end{array}$ & $\leq 0.10 \mathrm{gMS}_{\mathrm{t}}{ }^{2}$ & $\leq 0.12 \mathrm{gMSS}_{\mathrm{t}}^{2}$ & $\begin{array}{l}4 \text { sec window } \\
4 \text { sec sustained }\end{array}$ \\
\hline $\begin{array}{c}\text { Carbody Vertical } \\
\text { Acceleration (Transient) }\end{array}$ & $\leq 1.0 \mathrm{~g} \mathrm{P}-\mathrm{P}^{1}$ & $\leq 1.25 \mathrm{~g} \mathrm{P}-\mathrm{P}^{1}$ & 1 sec window \\
\hline $\begin{array}{c}\text { Carbody Vertical } \\
\text { Acceleration (Sustained } \\
\text { Oscillatory) } \\
\end{array}$ & \multicolumn{2}{|c|}{$\leq 0.25 \mathrm{gMS}_{\mathrm{t}}{ }^{2}$} & $\begin{array}{l}4 \mathrm{sec} \text { window } \\
4 \mathrm{sec} \text { sustained }\end{array}$ \\
\hline $\begin{array}{l}\text { Truck Lateral Acceleration } \\
\text { (Sustained Oscillatory) }\end{array}$ & \multicolumn{2}{|c|}{$\leq 0.30 \mathrm{gMS}_{\mathrm{t}}^{2}$} & $\begin{array}{l}2 \mathrm{sec} \text { window } \\
2 \mathrm{sec} \text { sustained }\end{array}$ \\
\hline $\begin{array}{c}\text { Single Wheel Vertical Load } \\
\text { Ratio }\end{array}$ & \multicolumn{2}{|c|}{$\geq 0.15$} & 5 foot window \\
\hline Single Wheel L/N & \multicolumn{2}{|c|}{$\leq{\frac{\tan (\delta)-0.5^{3}}{1+0.5 \tan (\delta)}}^{3}$} & 5 foot window \\
\hline Net Axle L/V & \multicolumn{2}{|c|}{$\leq 0.4+\frac{5.0}{V a}^{4}$} & 5 foot window \\
\hline Truck-side L/V & \multicolumn{2}{|c|}{$\leq 0.60$} & 5 foot window \\
\hline \multicolumn{3}{|c|}{$\begin{array}{l}{ }^{1} \text { Peak to peak value } \\
{ }^{2} \text { Root mean squared } \\
\text { with IInear trend } \\
\text { removed } \\
{ }^{3} 8 \text { - Flange angle } \\
{ }^{4} \mathrm{Va}-\text { Vortlcal axle } \\
\text { load In klps }\end{array}$} & \\
\hline
\end{tabular}

\section{VEHICLE QUALIFICATION}

In addition to revising standards for track geometry and VTI safety criteria, the FRA new final rule on VTI also enhances qualification procedures for demonstrating vehicle trackworthiness to take advantage of computer modeling. These procedures, which include use of simulations to demonstrate dynamic performance, are intended to give guidance to vehicle designers and provide a more comprehensive tool for safety assessment and verification of the suitability of a particular equipment design for the track conditions found in the U.S as discussed in this paper.

Figure 6 shows a summary of the test and simulation requirements for new vehicle types. The requirements depend upon the anticipated maximum operating speed and maximum cant deficiency. In general, the requirements for demonstrating safe performance increase as speed and cant deficiency increase. Since, under these conditions vehicle response can be larger and the consequence of a derailment can be more severe, instrumented wheelsets are required to measure wheel-rail forces on a track representative of the entire route planned for the intended operation.

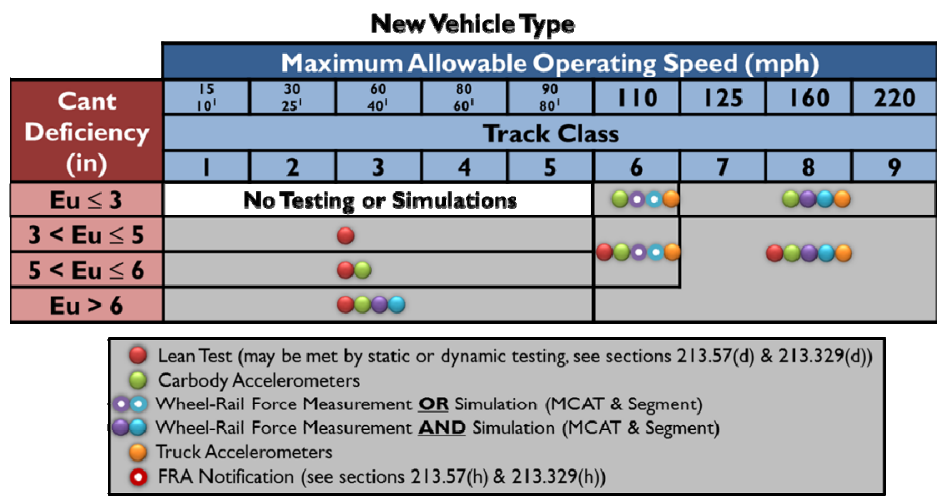

Figure 6: VTI Qualification Requirements (49 CFR 213.345)

As indicated, in some of these cases the FRA has included requirements for the use of computer simulations using an analytically defined minimally compliant track (MCAT), shown in Figure 7, during the vehicle qualification process as part of the assessment of vehicle performance (derailment tendency, stability, etc.). MCAT is used to model conditions not tested. The maximum allowable amplitudes discussed previously, which are generally not present on actual track, are used as inputs to the simulation. Such an analysis is intended to provide a good indication about how the equipment will behave when the track conditions become poorer than that present during the on-track testing. Furthermore, it allows a reduction in the amount of required testing when a piece of equipment is moved to another corridor. The combination of on-track testing and simulation can be extended and used to assess performance at lower speeds, particularly for vehicles that may have been designed for use in another area of the world. 


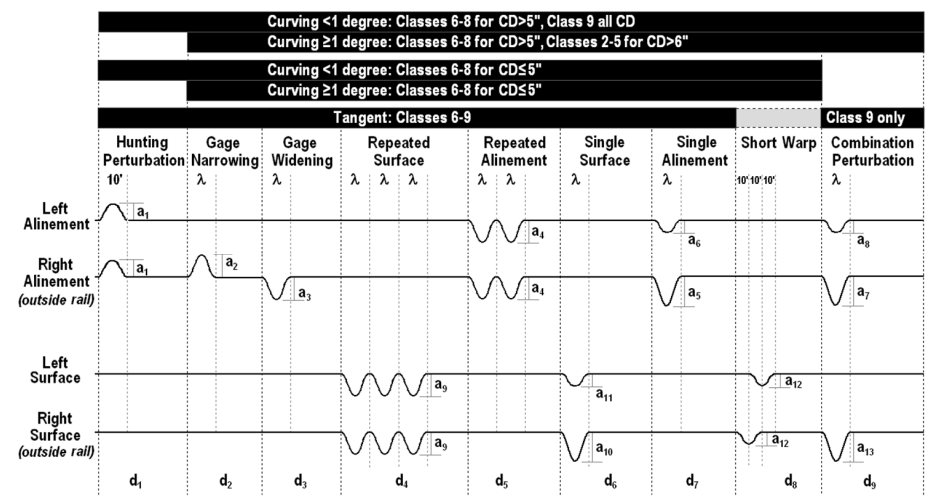

Figure 7: Minimally Compliant Analytical Track (MCAT)

\section{CONCLUDING REMARKS}

This paper describes differences in different international VTI standards in terms of track geometry limits and VTI safety criteria. Together these define the worst case track conditions that a vehicle must be designed to operate over safely and how well it must perform respectively. They become effectively constraints on the design of a vehicles suspension. The comparative study shown indicates differences that help to explain why certain equipment designed for operation in a particular region of the world may not perform as well when moved to another. Future work will consider a comparison of international testing and simulation procedures used for verifying trackworthiness (proper VTI performance) prior to certifying vehicles for operation.

\section{ACKNOWLEDGMENTS}

The work described in this paper was sponsored by the Office of Research and Development, Federal Railroad Administration (FRA), U.S. Department of Transportation, under the direction of Dr. John Tunna, Director of FRA Office of Research and Development.

\section{REFERENCES}

1. U.S. Department of Transportation, Federal Railroad Administration, 49 CFR Parts 213 and 238, Vehicle/Track Interaction Safety Standards; High-Speed and High Cant Deficiency Operations; Final Rule March 13, 2013. 